

\title{
Time of Eruption of Primary Dentition in Saudi Children
}

\section{Nasser M. Al-Jasser, BDS, MS; Lanre L. Bello, BDS, MS}

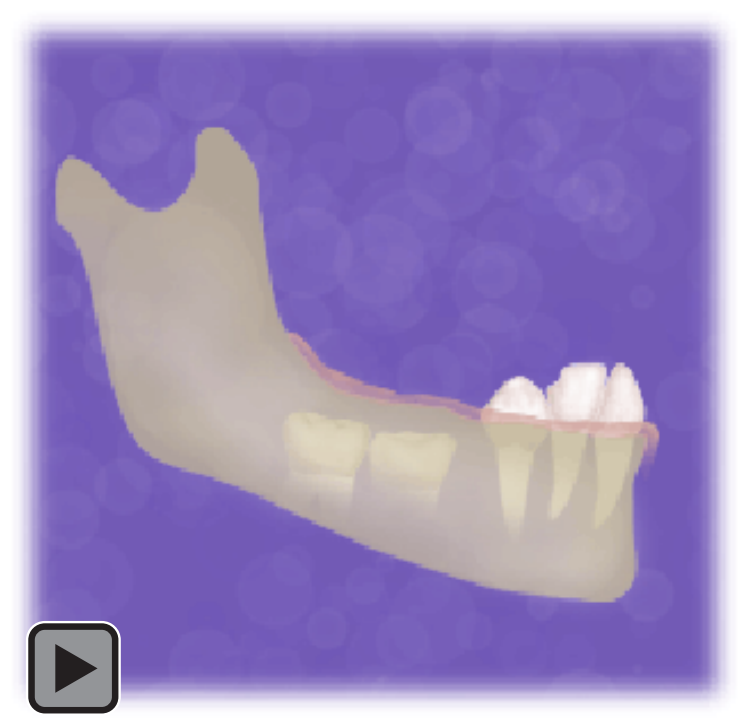

Abstract

The purpose of the present study was to determine the mean and standard deviation of eruption for primary dentition in children from Saudi Arabia and to compare it with another sample of full-term children who are clinically healthy between the ages of 4-40 months.

The results were significantly different from available literature on eruption patterns in children. Moreover, there is a slightly delayed eruption of primary teeth in Saudi children when compared to Caucasians. However, the order of eruption of primary teeth was the same as reported in other studies.

Keywords: Tooth eruption, dentition eruption

Citation: Al-Jasser NM, Bello LL. Time of Eruption of Primary Dentitionin Children from Saudi Arabia. J Contemp Dent Pract 2003 August;(4)3:065-075.

(C) Seer Publishing 


\section{Introduction}

The ages at which the primary teeth erupt are of great significance in relation to growth and development of the child. Most parents consider tooth eruption an important event in the child's development; hence, they often are anxious about timing and the sequence of eruption. Several studies have shown variations in the ages at which individual primary teeth erupt ${ }^{1-3}$ as well as variations of eruption patterns between different ethnic and racial groups. ${ }^{46}$ It is desirable to have suitable reference standards which ensure international comparability to assist clinicians in diagnosing cases of delayed or advanced tooth eruption. ${ }^{7,8}$ While mean ages of eruption for primary dentition have been determined for most population groups ${ }^{1-6}$, a review of the literature revealed no reported data on Saudi Arabian children.

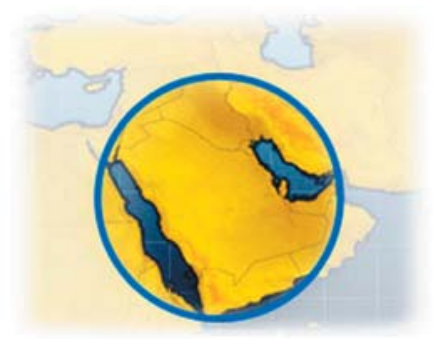

The purpose of this study was to determine the mean ages and standard deviation of eruption times for the primary dentition in Saudi children and to compare the eruption

times with other population groups.

\section{Subjects and Methods}

This study utilized a cross-sectional design. The study population was Saudi children attending the Child Health Services of King Khalid University Hospital and King Abdulaziz University Hospital, Riyadh, Saudi Arabia. The recruitment of children took place between June 1997 and May 1999. All selected children in this sample satisfied the following criteria:

- Full-term and clinically healthy

- Aged between 4 months and 40 months

- Saudi by nationality

The age of each child was ascertained from the birth certificate by calculating the chronological age in months from the date of birth. The nationalities of the children were verified from the place of birth using the national identity cards of both parents.



For purposes of this study, an erupted tooth was defined as any tooth with any part of its crown penetrating the gingiva and visible in the oral cavity. The determination of tooth eruption was carried out by Lanre L. Bello, BDS, MS, one of the authors, and a dental hygienist using a mouth mirror in a room with a good light source. The dental hygienist was adequately trained in the oral examination technique. The interrater reliability was determined in an initial examination of the first 20 children by the two examiners and the agreement was $100 \%$.

The data was transferred into a microcomputer for statistical analysis using the Statistical Program for Social Sciences (SPSS, version 9.0) and subjected to probit analysis. ${ }^{7}$ For each tooth, the percentage of eruption at various age levels was obtained and transformed into probit values from which the mean age and standard deviation of tooth eruption were estimated for males and females. The student t-test for independent samples was used to assess the

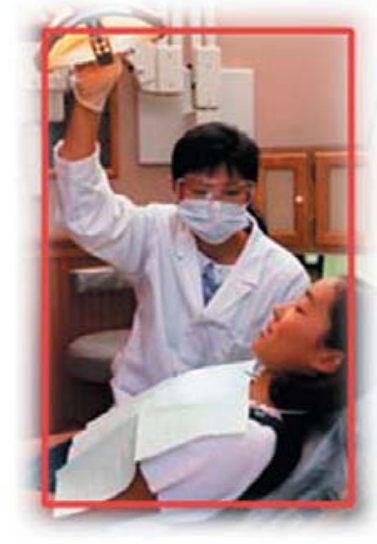
statistical significance of the difference in mean age of tooth eruption between males and females at the $5 \%$ probability level.

\section{Results}

There were a total of 728 children who met the inclusion criteria. The gender ratio of 1:1.09 favored male children. Tables $1 \mathrm{a}$ and $1 \mathrm{~b}$ show the 
mean time of eruption of primary teeth and their standard deviations for each category of tooth. For both the maxilla and mandible, there were no differences in the mean age of eruption of the teeth in the right and left sides; hence, they were combined. Thus, the summary statistics of the mean age of tooth eruption has been presented for both right and left sides.

The mandibular central incisors were the earliest category of teeth to erupt with a mean age of about 8.5 months for both genders. A standard deviation of 2.8 months suggests $68 \%$ of the children would have their teeth erupted between 5.7 months and 11.3 months. The maxillary central incisors erupted at about 11 months followed by the maxillary and mandibular laterals respectively. The first molars erupted on average earlier than the canines. The mandibular and maxillary second molars erupted at a mean age of about 28 months for both genders. The length of time from eruption of the first tooth to the last tooth was 19.5 months in the mandible and almost 17 months in the maxilla.
The phases of eruption of primary teeth were divisible into 4 active periods: incisors; first molars; canines; and second molars, with an interval of rest between the phases (Table 2). The first phase comprised central and lateral incisors that erupted within 6 months in both jaws for boys and girls (Table 1a and 1b). An interval of about 2.6 months in the mandible and 3.7 months in the maxilla followed before eruption of the first molars (phase 2). The third phase commenced with eruption of canines after a resting period of 3.9 months in the mandible and 4.2 months in the maxilla. The last phase was the eruption of the second molars that occurred after a pause of about 6.9 and 7.1 months in the mandible and maxilla respectively (Table 3 ).

Table 1a. Mean ages (months) at eruption \pm standard deviation (s.d.) of maxillary primary teeth in Saudi children.

\begin{tabular}{|l|l|l|l|l|l|l|}
\hline \multirow{2}{*}{ Tooth" } & \multicolumn{2}{|c|}{ Boys } & \multicolumn{2}{c|}{ Girls } & \multicolumn{2}{c|}{ Both Genders } \\
\hline & Mean & S.d. & Mean & S.d. & Mean & S.d. \\
\hline 51,61 & 11.19 & 1.90 & 11.20 & 1.90 & 11.20 & 1.90 \\
\hline 52,62 & 13.09 & 2.71 & 13.31 & 2.72 & 13.20 & 2.72 \\
\hline 53,63 & 21.14 & 3.65 & 21.03 & 3.66 & 21.09 & 3.66 \\
\hline 54,64 & 16.88 & 3.36 & 16.90 & 3.36 & 16.89 & 3.36 \\
\hline 55,65 & 28.16 & 4.17 & 28.25 & 4.19 & 28.21 & 4.18 \\
\hline
\end{tabular}

Table 1b. Mean ages (months) at eruption \pm standard deviation (s.d.) of mandibular primary teeth in Saudi children.

\begin{tabular}{|c|c|c|c|c|c|c|}
\hline & \multicolumn{2}{|c}{ Boys } & \multicolumn{2}{c|}{ Girls } & \multicolumn{2}{c|}{ Both Genders } \\
\hline 81,71 & 8.44 & 2.80 & 8.49 & 2.81 & 8.47 & 2.81 \\
\hline 82,72 & 14.44 & 3.60 & 14.61 & 3.60 & 14.53 & 3.60 \\
\hline 83,73 & 21.03 & 3.72 & 21.10 & 3.73 & 21.07 & 3.73 \\
\hline 84,74 & 17.17 & 2.72 & 17.13 & 2.73 & 17.15 & 2.73 \\
\hline 85,75 & 27.92 & 4.06 & 27.97 & 4.06 & 27.95 & 4.06 \\
\hline
\end{tabular}

* Tooth numbered according to FDI system 
There is a tendency for the teeth to erupt earlier in boys in both the maxilla and mandible. However, the difference was not statistically significant at the $5 \%$ confidence level.

The results of this study were compared to those of similar studies involving varying racial and ethnic groups. The results are presented in Tables $3 \mathrm{a}, 3 \mathrm{~b}, 4 \mathrm{a}$, and $4 \mathrm{~b}$; they suggest a slightly delayed eruption of the teeth in Saudi children compared to those of Caucasian children, but the results were similar to those reported for Iraqi children. The order of eruption of the primary teeth was the same as reported in all other studies.

\section{Discussion}

The mean times for eruption of primary teeth have been determined for most population groups. However, no reported data could be found for Saudi Arabia, and the standards for the eruption of deciduous teeth are based on non-Saudi population groups. A review of the literature shows there are differences in eruption times between populations. This is apparently due mainly to variations in the constitutions and environment of the groups investigated, thus, it becomes important to consider normal values of eruption for each population group.

The age of emergence of each primary tooth was established for both genders (Table 1 and Table

Table 2. Time intervals (months) between phases of teeth eruption in the maxilla and mandible in Saudi children.

\begin{tabular}{|c|c|c|c|c|c|c|}
\hline & \multicolumn{4}{|c|}{ Maxilla } & \multicolumn{3}{c|}{ Mandible } \\
\cline { 2 - 8 } & Boys & Girls & Both Genders & Boys & Girls & Both Genders \\
\hline Phase 1- Phase 2 & 3.8 & 3.6 & 3.7 & 2.7 & 2.5 & 2.6 \\
\hline Phase 2- Phase 3 & 4.3 & 4.1 & 4.2 & 3.9 & 4.0 & 3.9 \\
\hline Phase 3- Phase 4 & 7.0 & 7.2 & 7.1 & 6.9 & 6.9 & 6.9 \\
\hline
\end{tabular}

Table 3a. Mean ages (months) at eruption of maxillary primary teeth in boys.

\begin{tabular}{|c|cccc|}
\hline Tooth & Saudi & Iraq & Iceland & U.S. \\
\hline 51,61 & 11.19 & 10.70 & 8.99 & 9.36 \\
\hline 52,62 & 13.09 & 10.10 & 10.38 & 12.00 \\
\hline 53,63 & 21.14 & 18.80 & 17.59 & 21.00 \\
\hline 54,64 & 16.88 & 16.30 & 15.10 & 17.52 \\
\hline 55,65 & 28.16 & 26.00 & 26.13 & 30.96 \\
\hline
\end{tabular}

Table 3b. Mean ages (months) at eruption of mandibular primary teeth in boys.

\begin{tabular}{|c|cccc|}
\hline Tooth & Saudi & Iraq & Iceland & U.S. \\
\hline 81,71 & 8.44 & 9.20 & 8.03 & 7.20 \\
\hline 82,72 & 14.44 & 14.00 & 12.08 & 13.08 \\
\hline 83,73 & 21.03 & 19.00 & 19.16 & 20.88 \\
\hline 84,74 & 17.17 & 16.90 & 16.16 & 16.56 \\
\hline 85,75 & 27.92 & 26.00 & 25.62 & 30.00 \\
\hline
\end{tabular}


Table 4a. Mean ages (months) at eruption of maxillary primary teeth in girls.

\begin{tabular}{|ccccc|}
\hline Tooth & Saudi & Iraq & Iceland & U.S. \\
\hline 51,61 & 11.20 & 10.60 & 9.21 & 8.76 \\
\hline 52,62 & 13.31 & 11.40 & 10.16 & 11.76 \\
\hline 53,63 & 21.03 & 19.90 & 17.98 & 20.76 \\
\hline 54,64 & 16.90 & 16.40 & 14.95 & 16.32 \\
\hline 55,65 & 28.25 & 27.00 & 25.11 & 31.44 \\
\hline
\end{tabular}

Table 4b. Mean ages (months) at eruption of mandibular primary teeth in girls.

\begin{tabular}{|ccccc|}
\hline Tooth & Saudi & Iraq & Iceland & U.S. \\
\hline 81,71 & 8.49 & 8.40 & 6.89 & 7.68 \\
\hline 82,72 & 14.61 & 14.30 & 11.75 & 13.32 \\
\hline 83,73 & 21.10 & 20.30 & 18.14 & 20.52 \\
\hline 84,74 & 17.13 & 17.00 & 15.43 & 16.44 \\
\hline 85,75 & 27.97 & 25.10 & 23.74 & 29.52 \\
\hline
\end{tabular}

2), and the mean age and standard deviation for tooth eruption of all primary teeth in this study were compared with the results obtained in similar studies of other populations.

Tables $3 a$ and $3 b$, Tables $4 a$, and $4 b$ show the results published by other authors in primary teeth eruption, including our own results. The results suggested slightly delayed eruption of teeth in Saudi children compared to Caucasian children; but were similar to the findings from the Iraqi group. The order of eruption of primary teeth was the same as reported in all other studies.

Several studies have considered influential factors such as nutrition, socio-economic status, climate, and premature extraction of deciduous teeth on the time and order of the emergence of teeth, but the results were inconsistent. ${ }^{8,9}$ For example, Clemens et al. (1953) claimed the mean emergence times of children in a higher socio-economic group tended to be earlier than those in other children. ${ }^{10}$ Furthermore, other studies suggested a genetic origin for early or late emergence of teeth. ${ }^{11-14}$ But Lee et al. (1965) emphasized the inter-population differences seemed to have little meaning in themselves unless the socio-economic conditions, nutritional

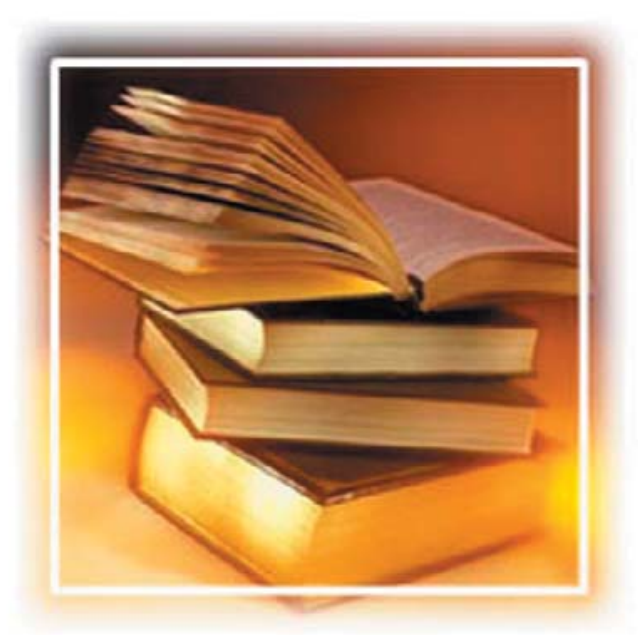

status, and other environmental factors in the survey were defined. ${ }^{15}$ Environmental factors such as the fluoride content in drinking water should be considered in evaluating differences in deciduous tooth emergence times between various geographic areas; even though Friedlaender and Bailit (1969) pointed out the relative unimportance of environmental influences in permanent dental emergence. ${ }^{16}$

With regard to the comparison between sexes, some authors do not find any significant differences in the population they investigated. ${ }^{17-20}$ But many other authors refer to statistically significant sex 
differences, at least for some teeth. ${ }^{21-24}$ We found a tendency for teeth to erupt earlier in boys for both jaws, although the difference was marginal. This is in agreement with the findings of some other authors. ${ }^{25-26}$ Also, all authors agree with our findings in regards to the sequence of eruption within the jaws. Many authors also agree the second molars most frequently erupt first in the mandible.



Nutrition

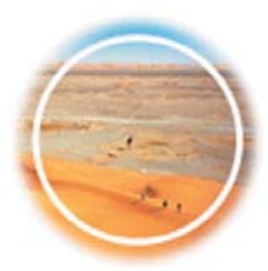

Climate
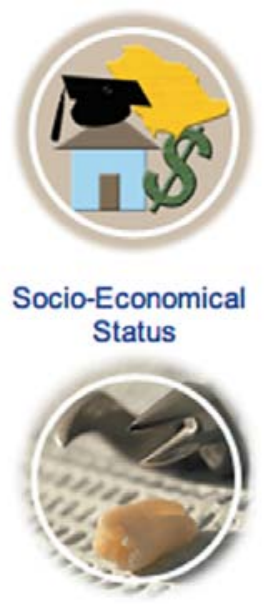

Premature Extraction

\section{Conclusion}

The main purpose of the present paper was to provide baseline data of eruption for primary dentition in children from Saudi Arabia. A delay in deciduous teeth eruption could be a sign of a systemic disease, and its observation may lead to a diagnosis of such diseases as hypothyroidism. Dental eruption ages have also been utilized in the study of the relationships between dental and skeletal maturation rates. ${ }^{27}$ The information obtained may also be important in a study of caries incidence as a guide to the length of time for which teeth have been exposed to possible attack by caries. ${ }^{28}$

If the results of this research prove valuable to dentists, physicians, and all those involved in the health care delivery of children, the objective of the paper would have been met. It is also our hope this paper would prove a useful basis of comparison for anthropologists.

\section{References}

1. Lysel L, Magnusson B, Thilander B. Time and order of eruption of the primary teeth. A longitudinal study. Odontol Revy 1962; 13:217-234.

2. Ramirez O, Planells P, Batberia E. Age and order of eruption of primary teeth in Spanish children. Community Dent Oral Epidemiol. 1994 Feb;22(1):56-9.

3. Hitchcock NE, Gilmour Al, Gracey M, et. al. Australian longitudinal study of time and order of eruption of primary teeth. Community Dent Oral Epidemiol. 1984 Aug;12(4):260-3.

4. Lunt RC, Law DB. A review of the chronology of eruption of deciduous teeth. J Am Dent Assoc. 1974 Oct;89(4):872-9. Review. No abstract available.

5. Baghdady VS, Ghose LJ. Eruption time of primary teeth in Iraqi children. Community Dent Oral Epidemiol. 1981 Oct;9(5):245-6. No abstract available.

6. Magnusson TE. Emergence of primary teeth and onset of dental stages in Icelandic children. Community Dent Oral Epidemiol. 1982 Apr;10(2):91-7.

7. Hayes RL; Mantel N. Procedures for computing the mean age of eruption of deciduous teeth. J Dent Res. 1958;38:938-947.

8. Lavelle CL. A note on the variation in the timing of deciduous tooth eruption. J Dent. 1975 Nov;3(6):267-70.

9. Robinow M. The eruption of deciduous teeth. Factors involved in timing. Env Child Health (Spec Issue) 1973; 19:200-5.

10. Clemens EMB, Davids-Thomas E, Pickett KG. Time of eruption of permanent teeth in British children in 1947-8. Br Med J 1953; 1:1421-1424.

11. Steggarde M, Hill TJ. Eruption times of teeth among Whites, Negroes and Indians. Am J Orthodont 1942; $28: 36-370$.

12. Eveleth PB, de Freitas JA. Tooth eruption and menarche of Brazilian-born children of Japanese ancestry. Hum Biol. 1969 May;41(2):176-84. No abstract available. 
13. Darlberg AA. Criteria of individuality in the teeth. J Forens Sci 1957; 2:389-421.

14. Houpt MI, Adu-Aryee S, Graninger RM. Eruption times of permanent teeth in the Brong Ahafo Region of Ghana. Am J Orthod. 1967 Feb;53(2):95-9. No abstract available.

15. Lee MMC, Low WD, Chang KS. Eruption of the permanent dentition of Southern Chinese children in Hong Kong. Arch Oral Biol. 1965 Nov-Dec;10(6):849-61. No abstract available.

16. Friedlaender JS, Bailit HL. Eruption times of the deciduous and permanent teeth of natives on Bougainville Island, Territory of New Guinea: a study of racial variation. Hum Biol. 1969 Feb;41(1): 51-65. No abstract available.

17. Roche AF, Barlela DH, Maritz JS. Deciduous eruption in Melbourne children. Aust Dent J 1964; 9:106-108.

18. Sandles HC. The eruption of deciduous teeth. J Pediatr 1944; 25:140-147.

19. Yun DJ. Eruption of primary teeth in Korean rural children. Am J Phys Anthropol 1957; 15:261-268.

20. McGregor IA, Thomson AM, Billewicz WZ. The development of primary teeth in children from a group of Gambian villages, and critical examination of its use for estimating age. $\mathrm{Br} \mathrm{J}$ Nutr. 1968 May;22(2):307-14. No abstract available.

21. Doering CR, Allen MF. Data on eruption and caries of primary teeth. Child Develop 1942; 13:113119.

22. Garn SM, Smith BH. Patterned asymmetry in tooth emergence timing. J Dent Res. 1980 Sep;59(9):1526-7. No abstract available.

23. Sato S, Ogiwara Y. Biostatistic study of the eruption order of deciduous teeth. Bull Tokyo Dent Coll. 1971 Feb;12(1):45-76. No abstract available.

24. Fergusson AD, Scott RB, Bowkin H. Growth and development of negro infants: comparison of deciduous dentition in Negro and White infants, a preliminary study. J Pediatr 1957; 50:327-331.

25. Nanda RS. Eruption of human teeth. Am J Orthodont 1960; 46(5):363-378.

26. Falknes F. Deciduous tooth eruption. Arch Dis Child 1957; 32:386-391.

27. Sutow WW, Terasaki T, Ohwada K. Comparison of skeletal maturation with dental status in Japanese children. Pediatrics 1954; 14(4):327-333.

28. Hadjimarkos DM. The epidemiological method as a research tool in dental caries. J Canad D Assoc 1956; 22(11):657-661.

\section{About the Authors}

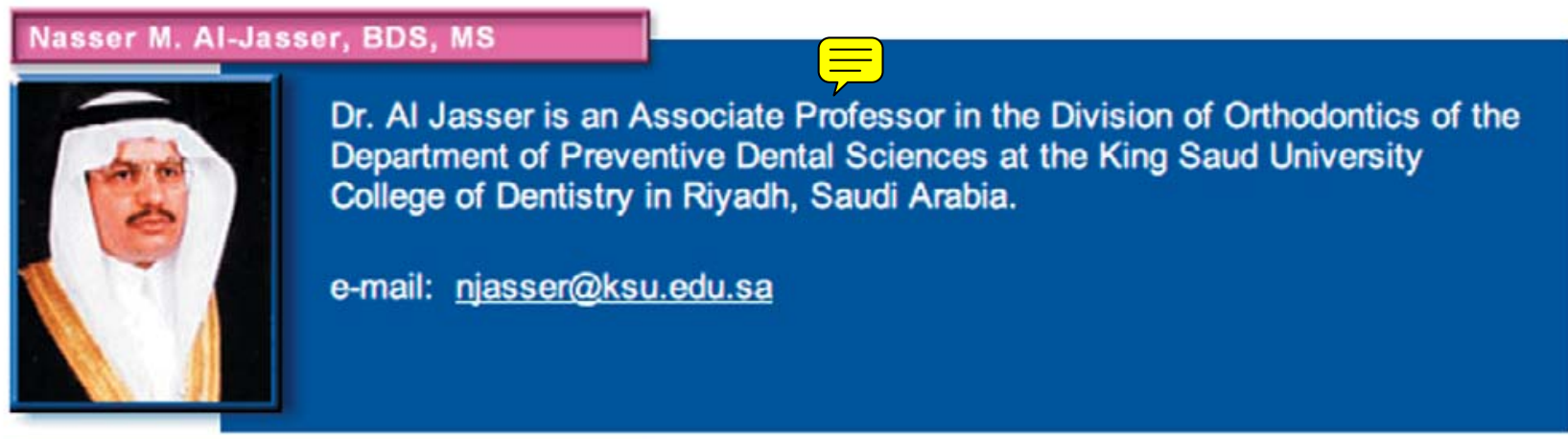

\section{Lanre L. Bello, BDS, MS}



